\title{
Primary lung tumors invading the chest wall
}

\author{
Pier Luigi Filosso ${ }^{1}$, Alberto Sandri ${ }^{1}$, Francesco Guerrera ${ }^{1}$, Paolo Solidoro ${ }^{2}$, Giulia Bora ${ }^{1}$, Paraskevas \\ Lyberis $^{1}$, Enrico Ruffini ${ }^{1}$, Alberto Oliaro ${ }^{1}$ \\ ${ }^{1}$ Department of Thoracic Surgery, University of Torino Italy, Torino, Italy; ${ }^{2}$ San Giovanni Battista Hospital, Service of Pulmonology, Via Genova, \\ Torino, Italy \\ Contributions: (I) Conception and design: PL Filosso, A Sandri, F Guerrera; (II) Administrative support: None; (III) Provision of study materials or \\ patients: G Bora, P Lyberis, E Ruffini, A Oliaro; (IV) Collection and assembly of data: PL Filosso; (V) Data analysis and interpretation: PL Filosso; (VI) \\ Manuscript writing: All authors; (VII) Final approval of manuscript: All authors. \\ Correspondence to: Pier Luigi Filosso, MD. Department of Thoracic Surgery, University of Torino Italy, Torino, Italy. Email: pierluigi.filosso@unito.it.
}

\begin{abstract}
Chest wall $(\mathrm{CW})$ involvement occurs in approximately $5 \%$ of all primary lung neoplasms. According to the most recent TNM classification, lung tumors invading CW are classified as T3, and they represent approximately $45 \%$ of all $\mathrm{T} 3$ lung cancers. The most common clinical symptom at presentation is chest pain (>60\%), which is highly specific of CW infiltration (>90\%). Dyspnoea and hemoptysis are also described, especially in case of large lesions. A realistic chance to cure locally advanced tumors invading $\mathrm{CW}$ is a surgical resection, consisting in the excision of the primary lung cancer along with the involved CW (sometimes an "en-bloc" resection) and an appropriate lymph-nodal dissection. However, such patients are at high-risk of facing postoperative complications; prognosis mainly depends on: (I) the completeness of resection; and (II) the lymph-nodal involvement. Hence, due to these reasons (incidence, symptoms, prognosis, post-operative complications), such category of patients are to be carefully assessed preoperatively and if deemed practicable, surgery should be taken into consideration. In this view, the aim of this paper is to critically review the most recent series of lung tumors invading the CW, with a particular focus on patients' preoperative evaluation, surgical techniques, postoperative complications and overall outcome.
\end{abstract}

Keywords: Primary lung cancer; chest wall resection; chest wall reconstruction; n2; induction therapy; adjuvant therapy

Submitted Mar 29, 2016. Accepted for publication Apr 13, 2016.

doi: $10.21037 /$ jtd.2016.05.51

View this article at: http://dx.doi.org/10.21037/jtd.2016.05.51

\section{Introduction}

Coleman described the first surgical management of a primary lung cancer invading the chest wall $(\mathrm{CW})$ in 1947 (1). Currently, the resection of a part of the CW is no more considered a challenging procedure and it is an accepted option to treat locally advanced pulmonary neoplasms. CW is involved in approximately $5 \%$ of all primary lung neoplasms and this clinical condition is more common than those of primary $\mathrm{CW}$ tumors that invade the lung (2).

The superior sulcus tumors (Pancoast tumors) represent $1 \%$ of primary lung cancers. In this paper, we will not treat Pancoast tumors since they will be subject of a specific chapter.

According to the most recent TNM classification, lung tumors invading $\mathrm{CW}$ are classified as $\mathrm{T} 3$, and they represent approximately $45 \%$ of all $\mathrm{T} 3$ lung cancers. Other pT3 neoplasms are: (I) lesions greater than $7 \mathrm{~cm}$ in size; (II) tumors with the presence of another ipsilobar nodule; (III) tumors invading the pericardium or the diaphragm.

Generally, there is a realistic chance to cure those locally advanced tumors if the surgical resection is performed, consisting in the excision of the primary lung cancer along with the involved CW (sometimes an "en-bloc" resection) and an appropriate lymph-nodal dissection. The prognosis mainly depends on: (I) the completeness of resection (R0); and (II) the lymph-nodal involvement. 


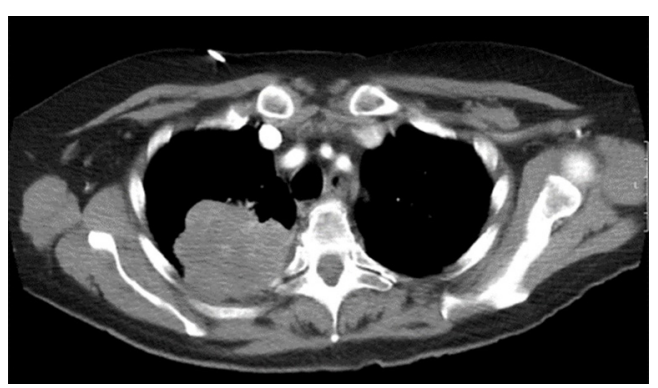

Figure 1 Lung cancer invading the paravertebral portion of the rib and the vertebral body.
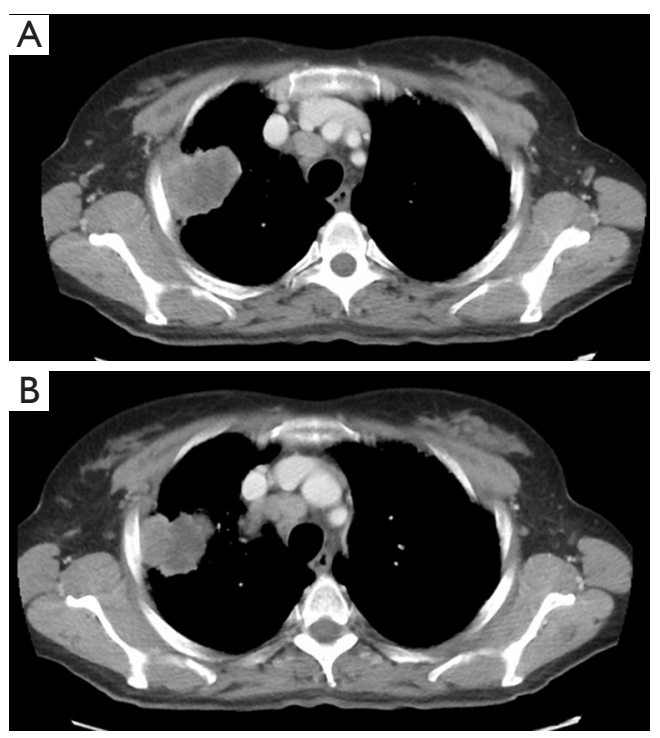

Figure 2 Right upper lobe squamous cell carcinoma with chest wall $(\mathrm{CW})$ invasion and mediastinal lymph-nodal involvement.

The aim of this article is to critically review the most recent series of lung tumors invading the $\mathrm{CW}$, with a particular focus in patients' preoperative evaluation, surgical techniques, postoperative complications and overall outcome.

\section{Clinical presentation and patients' preoperative evaluation}

$\mathrm{CW}$ infiltration usually originates from peripherally located tumors and develops gradually. At first, the tumor infiltrates the parietal pleura and progressively deepens into the soft tissue, the intercostal muscles and, finally, the ribs. If only the parietal pleura are infiltrated, an extrapleural resection (without muscles and ribs excision) is deemed sufficient, while a complete $\mathrm{CW}$ resection is required when a deeper invasion is observed.

Tumor size and depth of invasion are not always directly related; in fact, some large lesions may have a small depth of infiltration whereas smaller lesions may largely invade the $\mathrm{CW}$.

Generally, lung cancers invading the CW originate from the apico-posterior portion of the lung upper or lower lobes $(3,4)$ and, therefore, a posterolateral thoracotomy seems to be the best surgical approach. Instead, less frequently, tumors may originate laterally or antero-laterally for which an anterolateral thoracotomy or a sternotomy may be taken into account. Furthermore, lung cancers invading the paravertebral portions of the ribs or the vertebral bodies (Figure 1) are at high-risk for an incomplete resection.

The most common clinical symptom at presentation is chest pain (>60\%), which is highly specific of $\mathrm{CW}$ infiltration (>90\%). Dyspnoea and hemoptysis are also described, especially in case of large lesions. A careful patient's clinical examination, with meticulous attention to detect signs of tumour's infiltration and extension (e.g., weight loss, digital clubbing, and hypoxemia) is paramount in decision-making planning. A correct preoperative evaluation is fundamental to avoid tumor under staging, which may result in improper cures, unnecessary thoracotomies and delayed chemo/ radiotherapy (RT) treatments.

The initial diagnosis is usually obtained radiologically, although data published in literature clearly indicate that CT and MRI sensitivity and specificity are poor in absence of clear tumor infiltration signs. In fact, CT was accurate in $91 \%$ (5) and $50 \%$ (6) in diagnosis of T3 tumors, even if such data were obtained with less sophisticated radiological technologies than actual. The use of ultrasonography and especially respiratory dynamic MRI, with the demonstration of the independent $\mathrm{CW}$ and lungs movements during breathing, may be useful to rule out a possible invasion of the parietal pleura (7-9).

The preoperative accuracy is certainly improved by the use of PET scan, especially for the detection of hilar/ mediastinal lymph-nodal involvement (Figures 2,3) and distant metastases. Further invasive investigations such as mediastinoscopy or EBUS are indicated to rule out the suspect of lymph-nodal metastases. Nevertheless, the incidence of lymph-nodal involvement is not related to the depth of CW infiltration or to the tumor size.

Even with those sophisticated diagnostic tools, the final decision to perform an extrapleural or an en-bloc resection of the $\mathrm{CW}$ is very often made intraoperatively by the surgeon. 

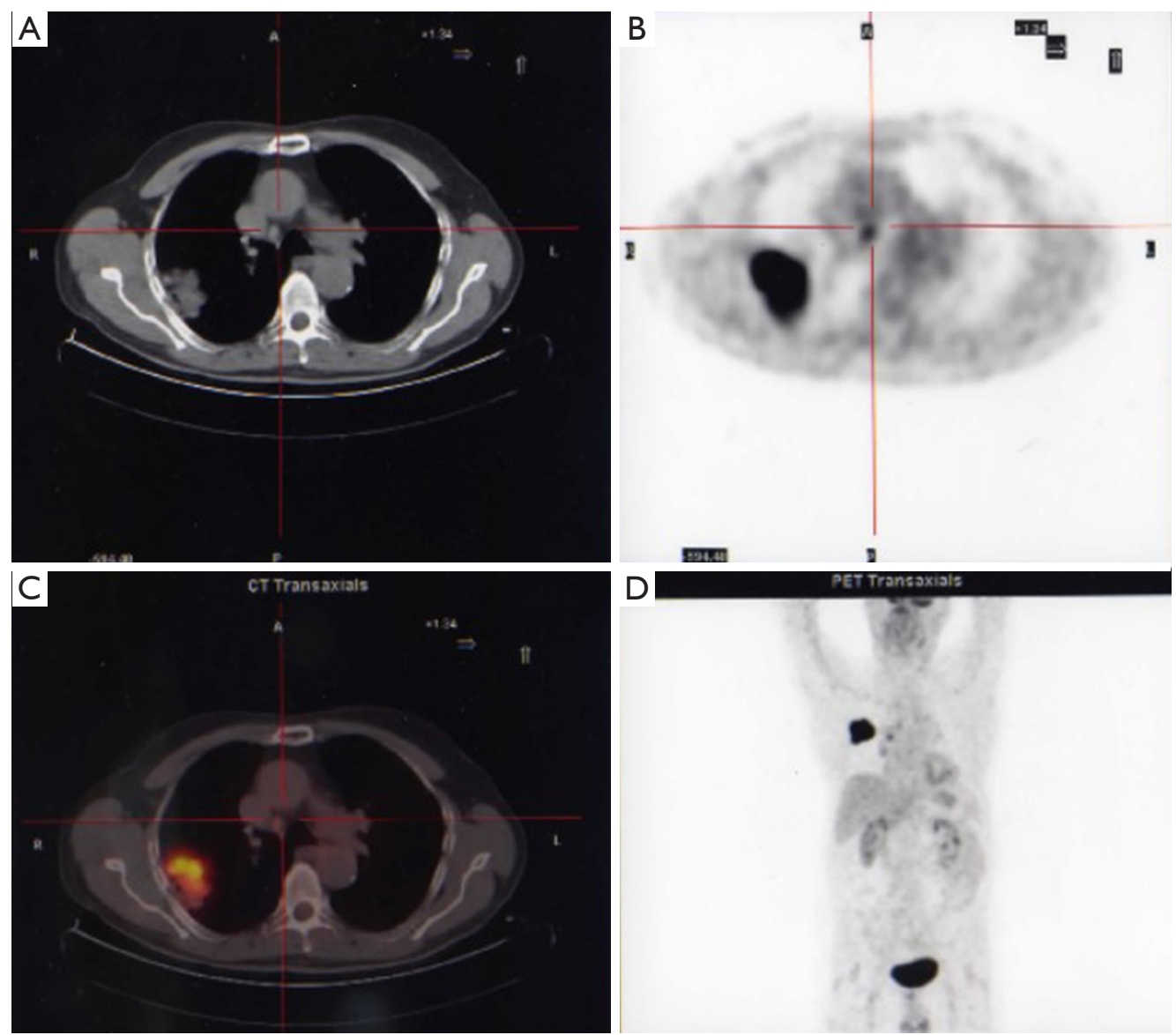

Figure 3 Preoperative FDG-PET scan showing mediastinal (right paratracheal region) lymph-nodal involvement in a right upper lobe adenocarcinoma with chest wall (CW) infiltration. FDG-PET, 18-Fluoro-deoxyglucose positron emission tomography.

In cT3 N1-2 patients, the risk of brain metastases is high: hence, it is reasonable, even if not mandatory, to perform brain CT/MRI in the workup staging of such patients.

Patients who undergo resection for locally advanced lung cancers are also at high-risk for postoperative complications and, therefore, require a careful preoperative assessment of comorbid diseases. Before planning surgery, acceptable pulmonary and cardiac reserve must be confirmed; static and dynamic respiratory function tests, along with perfusion scanning scintigraphy and echocardiography are generally indicated in the preoperative workup.

Since non-neoplastic pathologies (infections, tuberculosis, actinomycosis, hydatic cyst) or primary $\mathrm{CW}$ tumors with lung invasion may mimic $\mathrm{T} 3$ lung cancers with $\mathrm{CW}$ invasion, a preoperative cyto-histological confirmation is always required. The most common diagnostic tool to obtain a preoperative tumor diagnosis is a transthoracic fine needle aspiration biopsy (FNAB) or, sometimes, a tru-cut biopsy.
Bronchoscopy is necessary too, even if generally diagnostic in very large and central lesions, only.

\section{Surgical technique}

Due to the common posterior site, a classical posterolateral thoracotomy is very often the best surgical approach to lung neoplasms infiltrating the $\mathrm{CW}$.

Following the thoracotomy, the scapula is lifted with a retractor prior beginning the CW resection (Figure 4A). It is very important to access the chest far enough from the infiltrated area (Figure $4 B$ ); both the tumor and the CW should be carefully palpated to determine whether there is true infiltration/adhesions, as well as to circumscribe the boundaries (Figure 4C). The next step is the CW resection: it is recommended to proceed with the resection of one segment of the intact rib above and below the gross tumor margin and at least 3 or $4 \mathrm{~cm}$ laterally (10-12) (Figure 4D). 

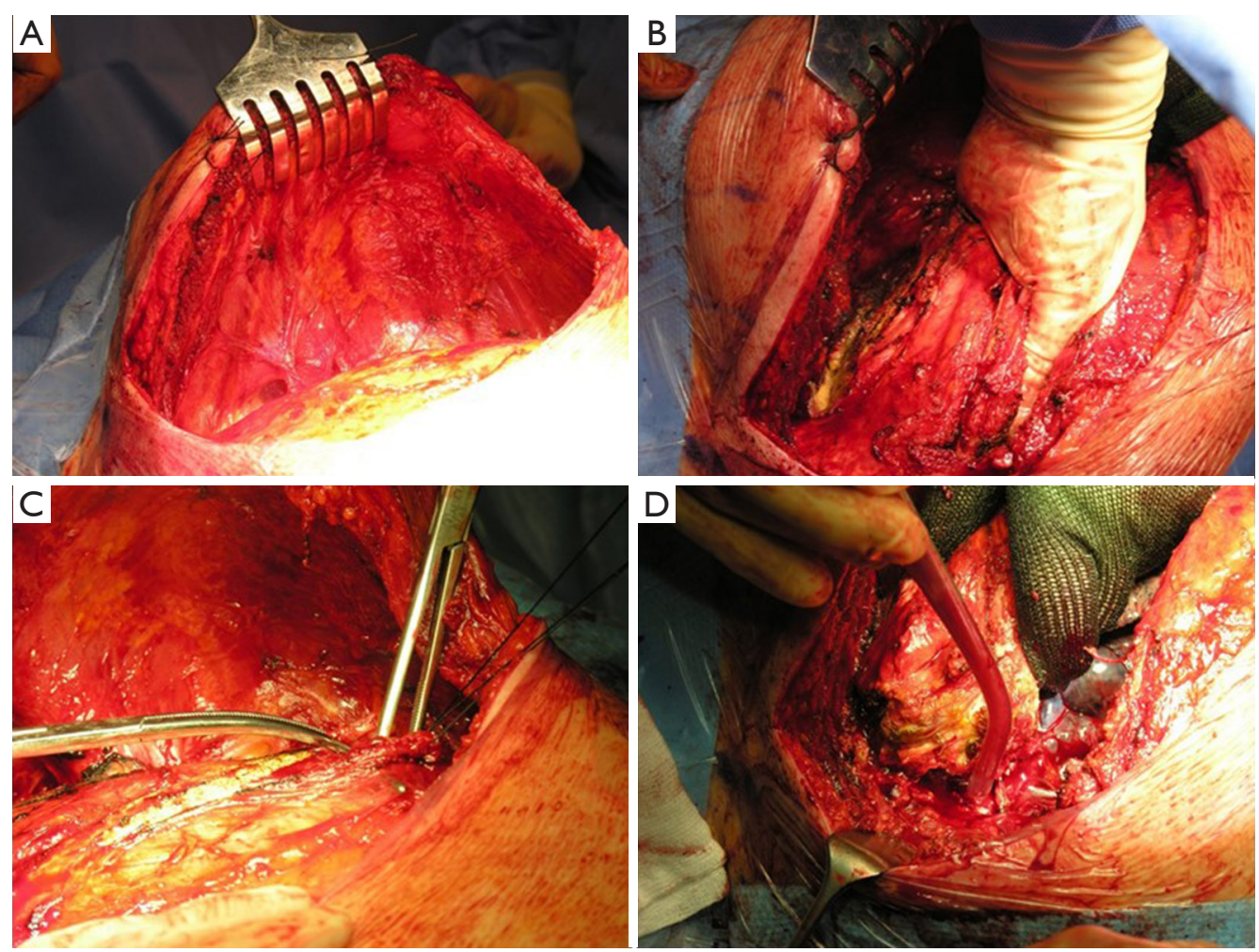

Figure 4 Surgical steps of chest wall (CW) resection.

A frozen section of the resected CW margin is not routinely recommended, due to the difficulties to obtain a correct diagnosis on bone histological specimens. In case of tumors with invasion of the paravertebral sulcus, the disarticulation of the rib from the vertebrae is required. Sometimes, the isolation of the spinal cord is required (Figure 5): its vascularization should be carefully preserved to avoid possible ischemic injuries. A multidisciplinary surgical approach with experienced neurosurgeons is the gold standard for the treatment of such invasive tumors.

After CW excision, the intervention proceeds with performing the classical pulmonary resection (usually a lobectomy) along with lymph-node exeresis (Figure 6).

$\mathrm{CW}$ reconstruction is a central time of the surgical procedure. The reconstructive principles are: (I) the maintenance of $\mathrm{CW}$ anatomy/structural stability; (II) the protection of vital organs exposed to rib resection; and (III) the preservation of the ventilatory mechanisms. The reported need of reconstruction may range from $40 \%$ (13) to $60 \%$ (14) of $\mathrm{CW}$ resections.

In general, small posterior defects $(\leq 3 \mathrm{~cm})$ that are covered by the scapula do not require reconstruction.
This must be performed in case of larger defects as well as when three or more ribs are resected, regardless its possible coverage by the scapula. In addition, if the defect is located below the tip of the scapula, reconstruction is also recommended, to avoid potential entrapment of the scapula in the defect, with consequent chest pain/discomfort and functional restrictions. Polypropylene (Figure 7) or polytetrafluoroethylene meshes are the most common materials used to reconstruct $\mathrm{CW}$ even after an extensive resection. The use of rigid prosthesis is not recommended since rigid materials tend to break due to continuous respiratory movements, with a high-risk to penetrate into the surrounding tissues (2).

New materials, more prone to be rapidly incorporated into the host, are currently available for $\mathrm{CW}$ reconstruction $(15,16)$ : malleable or articulating titanium bars $(17)$, cryopreserved homograft $(18,19)$ and acellular soft tissue patches of bovine, porcine or human derivation $(20,21)$, the latter ones characterized by near-physiological properties.

Synthetic tissue materials usually provide strong tissue reinforcement, but are at high-risk for potential foreign body reactions, which can sometimes result into serious 

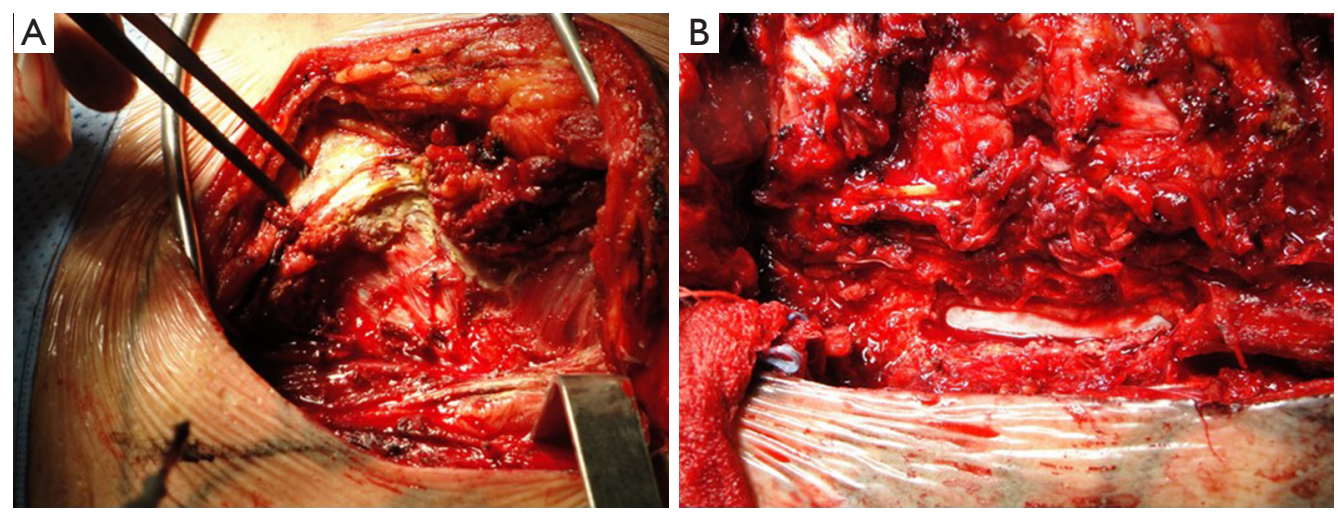

Figure 5 Surgical resection of an adenocarcinoma with posterior chest wall (CW) invasion: the spinal cord is isolated following the posterovertebral sulcus resection.
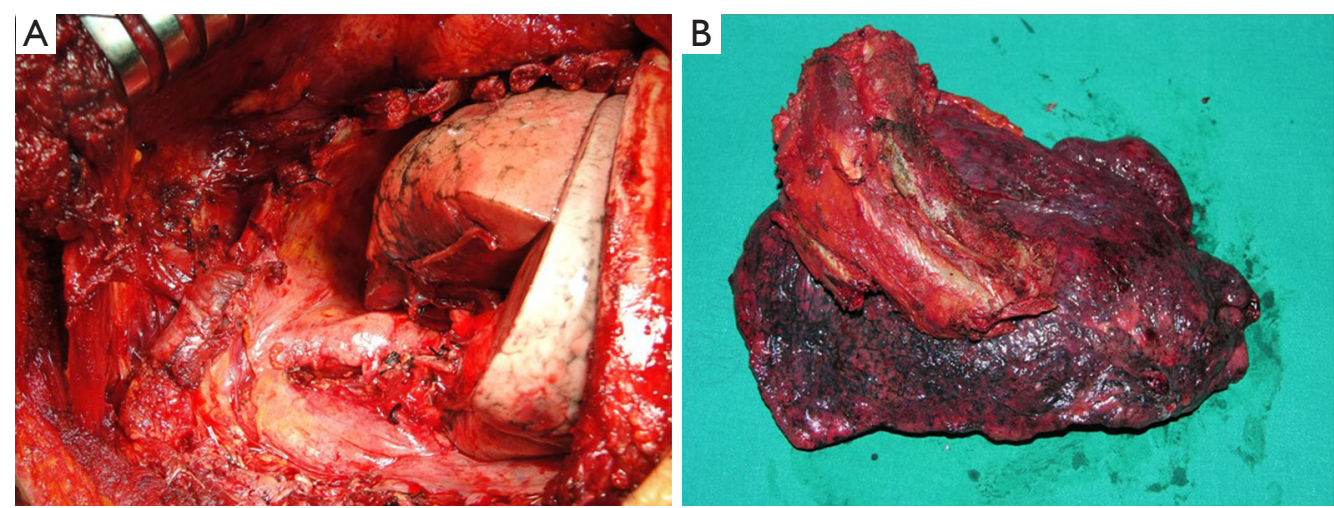

Figure 6 Right upper lobectomy with chest wall $(\mathrm{CW})$ resection.
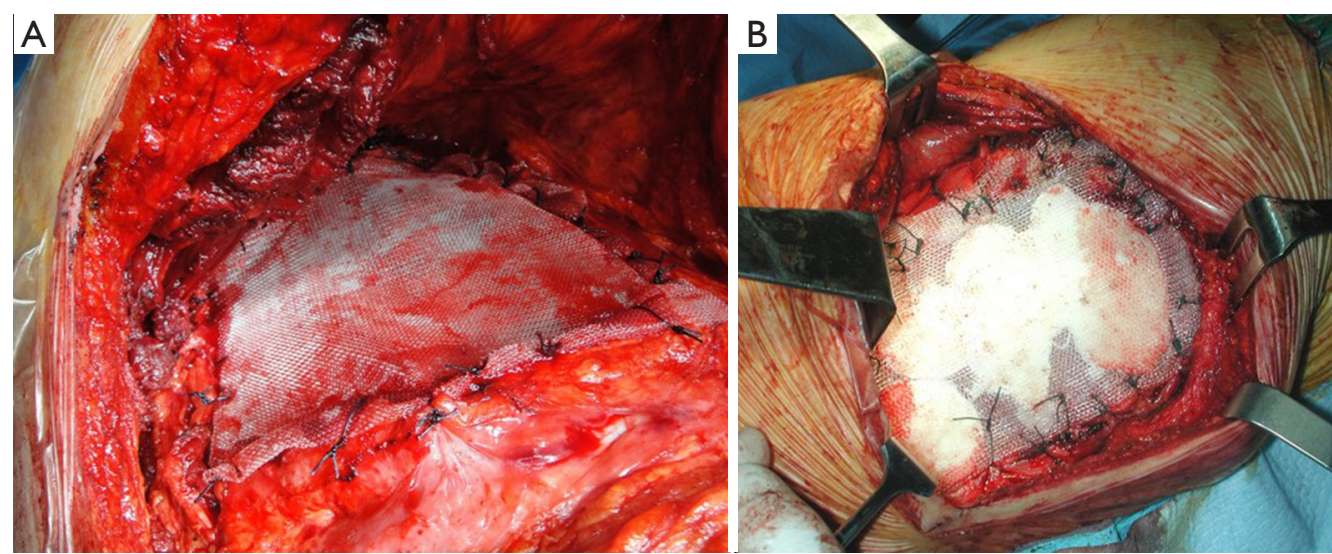

Figure 7 Posterior (A) and anterolateral (B) chest wall (CW) defects reconstructed with a polypropylene mesh. 
clinical complications.

Local infection is one of the most serious complications after $\mathrm{CW}$ resection/reconstruction: this may require reintervention for the removal of the prosthetic material, which is the most important way to control the infection sustained by a foreign body in situ (22). George et al. (20) suggest the use of XCM Biologic Tissue Matrix (Depuy Synthes, Oberdorf, Switzerland), acquired from the abdominal surgery experience (23), when the need of using prosthesis to restore $\mathrm{CW}$ rigidity and to avoid paradoxical respiratory movements, is identified. Seroma (Figure 8) is another surgical complication that is commonly treated with an elective drainage (often placed under ultrasound guidance), without the need to remove/replace the mesh. Finally, paraplegia is rarely described following costovertebral disarticulation, when the tumor invades the paravertebral sulcus (24), but it should be taken into account when such intervention is proposed to the patient.

\section{Results}

The median postoperative mortality following lung and

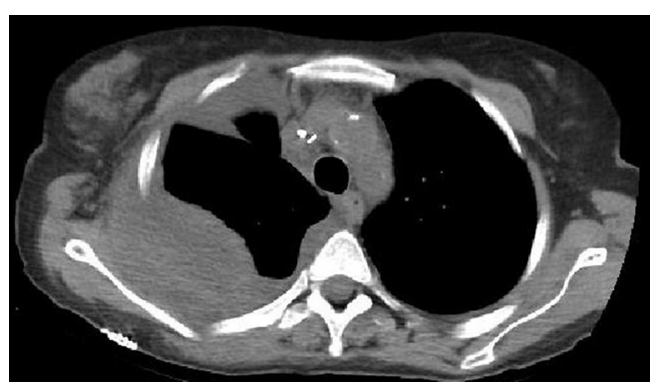

Figure 8 Chest wall (CW) seroma after right upper lobectomy with $\mathrm{CW}$ resection/reconstruction.
CW resection is nearly $6 \%$, which is currently 3 times higher than following a standard lobectomy. The main cause of death is respiratory failure (mainly caused by ARDSits incidence increases especially after extended resections-) or secretion retention, pneumonia and impaired cough (generally consequent to uncontrolled pain). Hence, pain and careful postoperative management and care are of great importance to those patients receiving a $\mathrm{CW}$ resection.

Long-term results for lung cancers invading $\mathrm{CW}$ are good, especially for pN0 ones. Table 1 summarizes the largest and most recent series published in the literature.

Local recurrences appear in $10-16 \%$ of cases $(10,12,14,26)$, whilst distant metastases are the main cause of death. Also, the number of resected ribs, as well as the grade of CW invasion, does not influence survival $(3,11,14,26)$. Contrariwise, resection of the involved $\mathrm{CW}$ demonstrated to have a strong impact on pain control and improving patient's quality of life.

The most important predictors of survival are: (I) the completeness of resection and (II) the absence of lymphnodal involvement. The median 5 -year survival rate for pT3 N0 patients is about $50 \%$; the presence of lymphnodal metastases worsens this rate up to $20-25 \%$ in N1 and below $10 \%$ in $\mathrm{N} 2$ patients (2). The frequency of lymphnodal involvement is not related to the tumor size and the depth of CW invasion. For some Authors, N2 involvement represents a strong contraindication to surgery and a recommendation to palliative treatments only (2). Presently, a cytologic or histologic N2 confirmation (EBUS or mediastinoscopy/mediastinotomy) in a potentially resectable T3 lung cancer (Figure 2) raises indication to neoadjuvant chemotherapy (CT). Its efficacy has been validated in Pancoast tumors $(2,28)$ but not in T3 tumors with CW invasion $(2,22)$. Induction CT is generally adopted in Stage

Table 1 Overall survival of the largest and most recent pT3 lung cancers with CW invasion

\begin{tabular}{|c|c|c|c|c|c|c|c|c|c|}
\hline Study (references) & Year & Pts. & N0 (\%) & N1 (\%) & N2 (\%) & 5-y NO (\%) & 5-y N1 (\%) & 5-y N2 (\%) & 5 -y overall (\%) \\
\hline Magdeleinat et al. (25) & 2001 & 195 & 58 & 26 & 13 & 25 & 20 & 21 & 21 \\
\hline Riquet et al. (12) & 2002 & 125 & 61 & 10 & 28 & 30 & 0 & 11 & 23 \\
\hline Matsuoka et al. (26) & 2004 & 76 & 52 & 13 & 34 & 44 & 40 & 65 & 34 \\
\hline Lin et al. (27) & 2006 & 42 & 65 & 32 & - & 39 & 17 & - & 28 \\
\hline
\end{tabular}

CW, chest wall. 
IIIA lung cancers mainly because of N2 disease, but the pT3 N2 subgroup has never been specifically tested. Future clinical trials should include such patients, before definitely excluding them from surgery.

Historically, adjuvant RT was proposed for T3 tumors, even in case of radical resection $(11,29)$; however, RT does not seem to be able to prevent local recurrences (30) and therefore it is no more recommended after radical resection, whilst it can be proposed after extrapleural lobectomy for neoplasms infiltrating only the parietal pleura, or in case of an incomplete resection (2).

In conclusion, primary lung cancers with $\mathrm{CW}$ invasion can be treated with surgery; a complete resection along with the absence of lymph nodal involvement is the most important prognostic factors. The median 5-year survival rate for $\mathrm{pT} 3 \mathrm{~N} 0$ patients is about $50 \%$. Induction $\mathrm{CT}$ is recommended when lymph nodal metastases are demonstrated; postoperative RT does not seem to prevent possible tumor recurrences, and therefore is proposed after an extrapleural or an incomplete resection.

\section{Acknowledgements}

None.

\section{Footnote}

Conflicts of Interest: The authors have no conflicts of interest to declare.

\section{References}

1. Coleman FP. Primary Carcinoma of the Lung, with Invasion of the Ribs: Pneumonectomy and Simultaneous Block Resection of the Chest Wall. Ann Surg 1947;126:156-68.

2. Stoelben E, Ludwig C. Chest wall resection for lung cancer: indications and techniques. Eur J Cardiothorac Surg 2009;35:450-6.

3. Elia S, Griffo S, Gentile M, et al. Surgical treatment of lung cancer invading chest wall: a retrospective analysis of 110 patients. Eur J Cardiothorac Surg 2001;20:356-60.

4. Martin-Ucar AE, Nicum R, Oey I, et al. En-bloc chest wall and lung resection for non-small cell lung cancer. Predictors of 60-day non-cancer related mortality. Eur J Cardiothorac Surg 2003;23:859-64.

5. Cangemi V, Volpino P, Drudi FM, et al. Assessment of the accuracy of diagnostic chest CT scanning. Impact on lung cancer management. Int Surg 1996;81:77-82 .

6. Gdeedo A, Van Schil P, Corthouts B, et al. Comparison of imaging TNM [(i)TNM] and pathological TNM [pTNM] in staging of bronchogenic carcinoma. Eur J Cardiothorac Surg 1997;12:224-7.

7. Akata S, Kajiwara N, Park J, et al. Evaluation of chest wall invasion by lung cancer using respiratory dynamic MRI. J Med Imaging Radiat Oncol 2008;52:36-9.

8. Kawaguchi K, Mori S, Usami N, et al. Preoperative evaluation of the depth of chest wall invasion and the extent of combined resections in lung cancer patients. Lung Cancer 2009;64:41-4.

9. Bandi V, Lunn W, Ernst A, et al. Ultrasound vs. CT in detecting chest wall invasion by tumor: a prospective study. Chest 2008;133:881-6.

10. Chapelier A, Fadel E, Macchiarini P, et al. Factors affecting long-term survival after en-bloc resection of lung cancer invading the chest wall. Eur J Cardiothorac Surg 2000;18:513-8.

11. Facciolo F, Cardillo G, Lopergolo M, et al. Chest wall invasion in non-small cell lung carcinoma: a rationale for en bloc resection. J Thorac Cardiovasc Surg 2001;121:649-56.

12. Riquet M, Lang-Lazdunski L, Le PB, et al. Characteristics and prognosis of resected $\mathrm{T} 3$ non-small cell lung cancer. Ann Thorac Surg 2002;73:253-8.

13. Doddoli C, D'Journo B, Le Pimpec-Barthes F, et al. Lung cancer invading the chest wall: a plea for en-bloc resection but the need for new treatment strategies. Ann Thorac Surg 2005;80:2032-40.

14. Akay H, Cangir AK, Kutlay H, et al. Surgical treatment of peripheral lung cancer adherent to the parietal pleura. Eur J Cardiothorac Surg 2002;22:615-20.

15. Rocco G. Overview on current and future materials for chest wall reconstruction. Thorac Surg Clin 2010;20:559-62.

16. Rocco G. Chest wall resection and reconstruction according to the principles of biomimesis. Semin Thorac Cardiovasc Surg 2011;23:307-13.

17. Hamad AM, Marulli G, Bulf R, et al. Titanium plates support for chest wall reconstruction with Gore-Tex dual mesh after sternochondral resection. Eur J Cardiothorac Surg 2009;36:779-80.

18. Dell'Amore A, Cassanelli N, Dolci G, et al. An alternative technique for anterior chest wall reconstruction: the sternal allograft transplantation. Interact Cardiovasc Thorac Surg 2012;15:944-7.

19. Marulli G, Hamad AM, Cogliati E, et al. Allograft sternochondral replacement after resection of large sternal chondrosarcoma. J Thorac Cardiovasc Surg 
2010;139:e69-70.

20. George RS, Kostopanagiotou K, Papagiannopoulos $\mathrm{K}$. The expanded role of extracellular matrix patch in malignant and non-malignant chest wall reconstruction in thoracic surgery. Interact Cardiovasc Thorac Surg 2014;18:335-9.

21. Rocco G, Serra L, Fazioli F, et al. The use of veritas collagen matrix to reconstruct the posterior chest wall after costovertebrectomy. Ann Thorac Surg 2011;92:e17-8.

22. Allen MS. Chest wall resection and reconstruction for lung cancer. Thorac Surg Clin 2004;14:211-6.

23. Smart NJ, Bloor S. Durability of biologic implants for use in hernia repair: a review. Surg Innov 2012;19:221-9.

24. Shamji MF, Maziak DE, Shamji FM, et al. Circulation of the spinal cord: an important consideration for thoracic surgeons. Ann Thorac Surg 2003;76:315-21.

25. Magdeleinat $P$, Alifano M, Benbrahem C, et al. Surgical treatment of lung cancer invading the chest wall: results

Cite this article as: Filosso PL, Sandri A, Guerrera F, Solidoro P, Bora G, Lyberis P, Ruffini E, Oliaro A. Primary lung tumors invading the chest wall. J Thorac Dis 2016;8(Suppl 11):S855S862. doi: $10.21037 /$ jtd.2016.05.51 and prognostic factors. Ann Thorac Surg 2001;71:1094-9.

26. Matsuoka H, Nishio W, Okada M, et al. Resection of chest wall invasion in patients with non-small cell lung cancer. Eur J Cardiothorac Surg 2004;26:1200-4.

27. Lin YT, Hsu PK, Hsu HS, et al. En bloc resection for lung cancer with chest wall invasion. J Chin Med Assoc 2006;69:157-61.

28. Rusch VW, Parekh KR, Leon L, et al. Factors determining outcome after surgical resection of T3 and T4 lung cancers of the superior sulcus. J Thorac Cardiovasc Surg 2000;119:1147-53.

29. Patterson GA, Ilves R, Ginsberg RJ, et al. The value of adjuvant radiotherapy in pulmonary and chest wall resection for bronchogenic carcinoma. Ann Thorac Surg 1982;34:692-7.

30. PORT Meta-analysis Trialists Group. Postoperative radiotherapy for non-small cell lung cancer. Cochrane Database Syst Rev 2005;(2):CD002142. 